\title{
BMJ Open Comparison of depression and anxiety between HIV-negative men who have sex with men and women (MSMW) and men who have sex with men only (MSMO): a cross-sectional study in Western China
}

Ying Hu, ${ }^{1}$ Xiao-ni Zhong, ${ }^{1}$ Bin Peng, ${ }^{1}$ Yan Zhang, ${ }^{1}$ Hao Liang, ${ }^{2}$ Jiang-hong Dai, ${ }^{3}$ Juying Zhang, ${ }^{4}$ Xiao-hua Zhong, ${ }^{5}$ Ai-long Huang ${ }^{6}$
To cite: Hu Y, Zhong $X$, Peng B, et al. Comparison of depression and anxiety between HIV-negative men who have sex with men and women (MSMW) and men who have sex with men only (MSM0): a cross-sectional study in Western China. BMJ Open 2019;9:e023498. doi:10.1136/ bmjopen-2018-023498

- Prepublication history for this paper is available online. To view these files, please visit the journal online (http://dx.doi. org/10.1136/bmjopen-2018023498).

Received 9 April 2018 Revised 12 November 2018 Accepted 20 November 2018

Check for updates

(C) Author(s) (or their employer(s)) 2019. Re-use permitted under CC BY-NC. No commercial re-use. See rights and permissions. Published by BMJ.

For numbered affiliations see end of article.

Correspondence to

Xiao-ni Zhong;

zxn133cq@sina.com

\section{ABSTRACT}

Objective To compare the prevalence of depression, anxiety and comorbidity between HIV-negative men who have sex with men and women (MSMW) and men who have sex with men only (MSM0) and examine the associated factors with depression and anxiety separately.

Design A cross-sectional study.

Setting The study was conducted in Western China. Participants From April 2013 to October 2014, 2422 participants aged 18-65 years, who were male at birth, had engaged in sex with male partners in the past 6 months, self-reported negative or unknown HIV status, were willing to participate and provided informed consent were recruited using non-probability sampling. An anonymous self-administered questionnaire was used to collect the data. A total of 1809 HIV-negative men who have sex with men (MSM) were eligible for the final analysis.

Results of 1809 MSM, $16.1 \%$ were MSMW and $83.9 \%$ were MSMO. The prevalence of depression, anxiety and comorbidity was $50.86 \%, 36.43 \%$ and $32.65 \%$, respectively, for MSMW; these results were higher than those for MSMO $(35.18 \%, 23.52 \%$ and $18.91 \%$, respectively). After adjusting for potential confounding factors, the prevalence of depression and anxiety was higher among MSMW than among MSMO. The prevalence of depression and/or anxiety was associated with young age, lower educational level, lower monthly income, lower HIV score and some risky sexual behaviour (had never engaged in HIV counselling, had obtained commercial sexual services in the past 6 months and sometimes/ always looked for sexual partners through the internet). The prevalence of depression and anxiety was lower for those who drank less than once a week than for those who never drank.

Conclusion Our findings suggest the need to address mental health among MSMW. Future health intervention strategies should integrate mental health services and traditional HIV prevention programmes and should consider the differences between MSMW and MSMO.
Strengths and limitations of this study

- This study is based on a large sample of men who have sex with men in Western China $(n=1809)$.

- Depression and anxiety were assessed using validated scales (The Center for Epidemiological Studies Depression Scale and the Self-Rating Anxiety Scale).

- However, the cross-sectional study design limits causal inferences.

- In addition to the serological status of HIV, other information was self-reported and the results for some sensitive issues may therefore be biased.

Trial registration number ChiCTR-TRC-13003849; Preresults.

\section{INTRODUCTION}

In 2015, men who have sex with men (MSM) accounted for $12 \%$ of new HIV infections globally. ${ }^{1}$ In China, MSM are at higher risk for new HIV infections, with the number of new HIV infections increasing from $487(2.5 \%)$ in 2006 to $34358(25.5 \%)$ in 2017 despite the wide variety of interventions that have been employed. ${ }^{23}$

Studies have shown that adverse mental health, such as depression and anxiety, is associated with HIV risk among MSM. ${ }^{4-8}$ For instance, MSM who report high levels of depressive symptoms are more likely to engage in condomless anal sex, ${ }^{9}{ }^{10}$ and anxiety has been identified as an independent predictor of sexual risk. ${ }^{11}$ Beyond HIV risk, depression or anxiety is also related to other adverse health outcomes such as low adherence to antiretroviral therapy, ${ }^{12}$ suicidal thoughts $^{13-15}$ and some lifelong chronic 
diseases. ${ }^{16}$ Moreover, comorbidity of depression and anxiety is very common and has been reported in many studies, ${ }^{17-19}$ and this comorbidity can increase the severity and course of an injury. Although many studies have investigated mental health among MSM, little research has focused on the differences between men who have sex with men and women (MSMW) and men who have sex with men only (MSMO).

It is necessary and important to distinguish MSMW from MSM, especially in China. Because marriage between males is illegal, and due to the prevalence of the traditional Chinese value of 'having a son to carry on the family name', many MSM must eventually marry and have sex with women, leading to a relatively high proportion of MSMW in China. One study conducted in Beijing, the capital city of China, reported that of 1141 MSM, $45.6 \%$ were MSMW and marriage was a strong predictor of being in this group. ${ }^{20}$ Hence, we hypothesise that the environment in which MSMW and MSMO live and the experiences they have may differ, which may contribute to different levels of mental health.

Some studies have found differences between MSMW and MSMO in HIV-related risky sexual behaviour (eg, unprotected anal sex and unprotected oral sex) and HIV testing, ${ }^{21}{ }^{22}$ but few studies have focused on the different levels of mental health between MSMW and MSMO. When MSM are grouped based on self-identified sexual orientation (gay or bisexual), the prevalence of depression is inconsistent. In a survey involving 1367 MSM in Mexico, the prevalence of depression was lower in bisexuals than in gay individuals. ${ }^{23}$ However, Jorm et $a l^{24}$ obtained the opposite findings, and Millar et $a l^{25}$ did not find an association. Some self-identified gay men may still have sex with women, especially in China. Dyer $e t a t^{26}$ found that $75 \%$ of MSMO identified themselves as gay while $72 \%$ of MSMW identified themselves as bisexual, suggesting that self-identified sexual orientation is not consistent with actual sexual behaviour (MSMW or MSMO). We consider a classification based on actual sexual behaviour more realistic.

Another point that should be noted is that some studies have targeted the HIV-positive (HP) MSM population to explore their mental health, ${ }^{27} 28$ while others have not distinguished HP MSM from HIV-negative (HN) MSM populations. ${ }^{15} 29$ The levels of mental health in these two MSM populations with different HIV serological status may be different. Considering these conditions, we targeted only the HN MSM population in this study. In this study, we (1) compare the prevalence of depression, anxiety and comorbidity between HN MSMW and HN MSMO and (2) examine the associated factors for depression and anxiety separately for MSM.

\section{METHODS}

\section{Participants and procedures}

This study was a cross-sectional analysis of an open, randomised, multicentre, parallel controlled clinical intervention trial conducted in Western China to evaluate HIV pre-exposure prophylaxis. From April 2013 to October 2014, a total of 2422 participants were recruited using non-probability sampling in Chongqing (Chongqing City, Wanzhou District), Sichuan (Mianyang, Nanchong, Suining, Yibin and Luzhou cities), Xinjiang (Wulumuqi and Yili cities) and Guangxi (Nanning, Liuzhou and Beihai cities) in Western China. Specifically, we advertised on gay websites and in QQ groups and we cooperated with local non-governmental organisations that provide information about HIV prevention, counselling and testing for lesbian, gay, bisexual and transgender individuals in each site. We followed this approach to introduce detailed information (purpose, process, potential benefits and risks) about this study to the leaders to gain their support and, with their assistance, to recruit participants from the organisations. The participants were also encouraged to invite their friends who met the criteria. Participants aged 18-65 years, who were male at birth, had engaged in sex with male partners in the past 6 months, self-reported negative or unknown HIV status, were willing to participate and provided informed consent were recruited.

After informed consent was obtained, an anonymous self-administered questionnaire was used to collect the data. If the participants encountered any unclear terms, the trained investigator explained the terms to them. All questionnaires were then checked for both completeness and consistency. After completing the survey, the participants' HIV serological status was determined by HIV serological tests. First, antigens and antibodies were screened with the fourth-generation ELISA from Beijing Kewei Clinical Diagnostic Reagent. If the test was positive, the specimens were retested using the HIV 1+2 antibody diagnostic kit (Electroselenium method). If the result of the retest was positive, an HP result was reported. Each participant was compensated $¥ 80$ for transportation and breakfast.

\section{Patient and public involvement}

No patients were involved in the design, recruitment and conduct of this study. An anonymous questionnaire was used to collect data. All participants agreed the results of the study will be published in the form of articles with no personal information.

\section{Measures}

\section{Definitions of MSMW and MSMO}

All participants were asked to provide the number of their male partners in the past 6 months, including regular partners and casual partners, and the number of their female sexual partners in the past 6 months. If the number of female sexual partners was 0 , the participant was considered to be part of the MSMO group, while a number greater than 0 indicated that the participant was in the MSMW group in this study. 


\section{Demographic characteristics}

Demographic characteristics included age, household registration, educational level, marital status and average monthly income.

\section{HIV-related characteristics}

A variety of characteristics related to HIV were assessed, including HIV knowledge scores, which consisted of 13 items relating to the transmission and infection of HIV. Scores greater than or equal to 11 were considered to reflect a better understanding of HIV knowledge based on the criteria that a correct answer received a score of 1 point, while a wrong answer or 'don't know' answer received a score of 0 . The participants were asked about HIV testing and HIV counselling (have you ever engaged in HIV testing and counselling), their perception of HIV severity, their perception of the rates of HIV infection among MSM in the city where they lived and their perception of the threat of HIV to themselves and their families. The participants were also asked about their sexual role (only ' 1 ', both ' 1 ' and ' 0 ', only ' 0 '), whether they had unprotected anal and oral sex with male partners in the past month, whether they had looked for sexual partners through the internet, whether they had obtained commercial sexual services, and whether they had been diagnosed with a sexually transmitted disease (STD) by doctors in the past 6 months.

\section{Substance use}

Substance use included the use of alcohol and illicit drugs. The participants were asked about their frequency of drinking. The responses ranged from 'never' to 'almost every day' in the last month.

Illicit drug use was assessed by asking the participants whether they had used drugs (ecstasy, methamphetamine, ketamine, opium, cannabis, heroin, pethidine, morphine and other illicit drugs) in the past 6 months. Participants who reported using any one of these drugs were classified as 'yes'.

\section{Depression}

Depression was evaluated using the Center for Epidemiological Studies Depression Scale, ${ }^{30}$ which is used primarily in epidemiological investigations to screen out participants with depression for further diagnosis. Many studies have demonstrated the reliability and validity of the scale. ${ }^{31-33}$ The scale consists of 20 items, and the participants were asked to give scores of 0 (occasionally or no) to 3 (most of the time) for each item based on how frequently they experienced the corresponding feeling in the past week (eg, 'I felt that I was struggling with everything' and 'I felt lonely'). Of these items, four were scored in reverse order ( 3 to 0 ), and the scores for the 20 items were aggregated. Scores equal to or greater than 16 points indicated the likely presence of clinical depression, and higher scores indicated greater levels of depressive symptoms. The standardised Cronbach's $\alpha$ in this study was 0.87 .

\section{Anxiety}

Anxiety was measured using the Self-Rating Anxiety Scale $^{34}$ and studies have shown the substantial reliability and validity of this scale. ${ }^{35}$ The scale consists of 20 items scored on a four-point scale ranging from 1 (no or very little time) to 4 (most or all the time) according to the frequency of the respondent's personal experience (eg, 'I felt scared for no reason', 'I felt likely to be mad') in the past week. Of these items, five were reverse scored. The scores for the 20 items were aggregated into a raw score, and a standard score was obtained by multiplying the raw score by 1.25 and then taking the integer. Scores equal to or greater than 50 indicated anxiety and higher scores indicated greater levels of anxiety symptoms. The standardised Cronbach's $\alpha$ in this study was 0.86 .

\section{Statistical analysis}

Differences in demographic and HIV-related characteristics between the MSMW and MSMO were analysed using the $\chi^{2}$ test or rank-sum test. Scores for depression and anxiety were reported using the mean $\pm \mathrm{SD}$, median and range. Comparisons of the scores between the MSMW and MSMO were performed using the rank-sum test, while comparisons between the MSMW and MSMO regarding the prevalence of depression, anxiety and comorbidity were performed using the $\chi^{2}$ test. The variables were screened using stepwise regression in multivariate logistic regression analysis. $\mathrm{P}<0.05$ was considered statistically significant. All statistical analyses were performed using SAS V.9.4 software.

\section{RESULTS}

From April 2013 to October 2014, 2422 participants were recruited in Chongqing, Sichuan, Guangxi and Xinjiang. In total, 613 MSM were excluded due to the reasons shown in figure 1 . Among the eligible sample of 1809 MSM, 1518 (83.9\%) were classified as MSMO, and

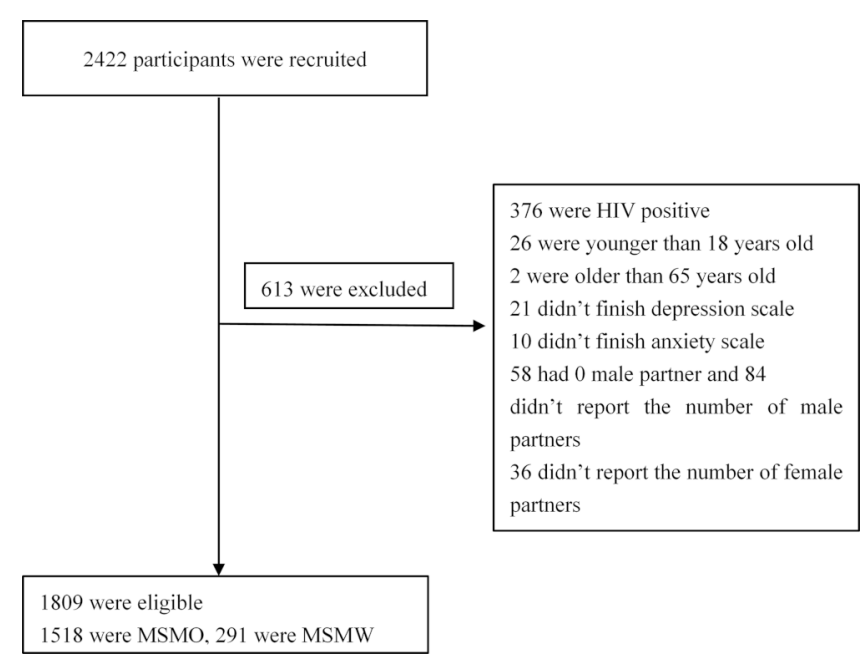

Figure 1 Flow chart of participants' enrolments. MSMO, men who have sex with men only; MSMW, men who have sex with men and women. 
Table 1 Demographics, HIV-related characteristics, substance use between MSMW and MSMO

\begin{tabular}{|c|c|c|c|c|c|}
\hline \multirow[b]{2}{*}{ Variable } & \multirow{2}{*}{$\begin{array}{l}\text { MSMO (n=1518) } \\
n(\%)\end{array}$} & \multirow{2}{*}{$\begin{array}{l}\text { MSMW (n=291) } \\
\mathrm{n}(\%)\end{array}$} & \multirow[b]{2}{*}{$P$ value } & \multicolumn{2}{|l|}{ Multivariate analysis } \\
\hline & & & & Adjusted OR $(95 \% \mathrm{Cl})$ & $P$ value \\
\hline Age & & & $<0.01^{*}$ & & \\
\hline 18-25years old & $619(40.78)$ & $52(17.87)$ & & & \\
\hline 26-35 years old & 604 (39.79) & $104(35.74)$ & & & \\
\hline Older than 35 years old & 295 (19.43) & $135(46.39)$ & & & \\
\hline Household registration & & & $<0.01 \dagger$ & & \\
\hline Urban & $1115(73.6)$ & 175 (61.19) & & Ref & \\
\hline Rural & $400(26.4)$ & $111(38.81)$ & & 1.70 (1.22 to 2.38$)$ & $<0.01$ \\
\hline Educational levelł & & & $<0.01^{*}$ & & \\
\hline Primary or below & $37(2.44)$ & $19(6.53)$ & & & \\
\hline Junior high & $125(8.25)$ & $50(17.18)$ & & & \\
\hline Senior high & $379(25)$ & $93(31.96)$ & & & \\
\hline Junior college & $376(24.8)$ & $59(20.27)$ & & & \\
\hline College or above & 599 (39.51) & $70(24.05)$ & & & \\
\hline Marital status & & & $<0.01 \dagger$ & & \\
\hline Unmarried & $1258(82.87)$ & $86(29.55)$ & & Ref & \\
\hline Married & $132(8.7)$ & $184(63.23)$ & & $19.93(14.13$ to 28.10$)$ & $<0.01$ \\
\hline Divorced/widowed & $128(8.43)$ & $21(7.22)$ & & 2.45 (1.42 to 4.23$)$ & $<0.01$ \\
\hline Monthly income (¥)‡ & & & $0.09^{*}$ & & \\
\hline$\leq 1000$ & 264 (17.59) & $30(10.34)$ & & & \\
\hline $1001-3000$ & $532(35.44)$ & $114(39.31)$ & & & \\
\hline $3001-5000$ & $516(34.38)$ & $111(38.28)$ & & & \\
\hline$\geq 5001$ & 189 (12.59) & $35(12.07)$ & & & \\
\hline HIV knowledge score & & & $<0.01 \dagger$ & & \\
\hline$<11$ & $1063(70.03)$ & $236(81.1)$ & & Ref & \\
\hline$\geq 11$ & $455(29.97)$ & 55 (18.9) & & 0.65 (0.44 to 0.96$)$ & 0.03 \\
\hline HIV testing $\ddagger$ & & & $<0.01 \dagger$ & & \\
\hline No & $323(21.33)$ & $88(30.34)$ & & & \\
\hline Yes & $1191(78.67)$ & $202(69.66)$ & & & \\
\hline HIV counselling & & & $0.01 \dagger$ & & \\
\hline No & $581(38.38)$ & $135(46.39)$ & & & \\
\hline Yes & $933(61.62)$ & $156(53.61)$ & & & \\
\hline Perceived AIDS severity & & & $0.19 \dagger$ & & \\
\hline High & 939 (61.9) & $192(65.98)$ & & & \\
\hline Moderate and low & $578(38.1)$ & 99 (34.02) & & & \\
\hline $\begin{array}{l}\text { Perceived the rate of HIV } \\
\text { infection among MSM in the } \\
\text { city where they livef }\end{array}$ & & & $0.72 \dagger$ & & \\
\hline High & $325(21.45)$ & $65(22.41)$ & & & \\
\hline Moderate and low & $1190(78.55)$ & 225 (77.59) & & & \\
\hline Perceived HIV threat to thems & ves and their famili & & $<0.01 \dagger$ & & \\
\hline High & $808(53.26)$ & $193(66.78)$ & & Ref & \\
\hline Moderate and low & 709 (46.74) & $96(33.22)$ & & 0.68 (0.49 to 0.95$)$ & 0.03 \\
\hline Sexual role $\neq$ & & & $<0.01 \dagger$ & & \\
\hline Only '1' & 371 (24.49) & 103 (35.76) & & & \\
\hline
\end{tabular}

Continued 
Table 1 Continued

\begin{tabular}{|c|c|c|c|c|c|}
\hline \multirow[b]{2}{*}{ Variable } & \multirow{2}{*}{$\begin{array}{l}\text { MSMO (n=1518) } \\
n(\%)\end{array}$} & \multirow{2}{*}{$\begin{array}{l}\text { MSMW (n=291) } \\
\mathrm{n}(\%)\end{array}$} & \multirow[b]{2}{*}{$P$ value } & \multicolumn{2}{|l|}{ Multivariate analysis } \\
\hline & & & & Adjusted OR $(95 \% \mathrm{Cl})$ & $P$ value \\
\hline ' 1 ' and ' 0 ' & $977(64.49)$ & $174(60.42)$ & & & \\
\hline Only '0' & $167(11.02)$ & $11(3.82)$ & & & \\
\hline $\begin{array}{l}\text { Unprotected anal sex with male } \\
\text { partners in the past month } \ddagger\end{array}$ & & & $0.12 \dagger$ & & \\
\hline No & $1053(73.48)$ & $216(77.98)$ & & & \\
\hline Yes & $380(26.52)$ & $61(22.02)$ & & & \\
\hline $\begin{array}{l}\text { Unprotected oral sex with male } \\
\text { partners in the past month } \ddagger\end{array}$ & & & $<0.01 \dagger$ & & \\
\hline No & $502(34.6)$ & $128(46.55)$ & & Ref & \\
\hline Yes & $949(65.4)$ & $147(53.45)$ & & 0.54 (0.39 to 0.74$)$ & $<0.01$ \\
\hline $\begin{array}{l}\text { Looking for sexual partners } \\
\text { through the internet in the past } \\
6 \text { months } \neq\end{array}$ & & & $0.52^{*}$ & & \\
\hline Never & $570(37.6)$ & $99(34.14)$ & & & \\
\hline Occasionally & $586(38.65)$ & $124(42.76)$ & & & \\
\hline Sometimes/always & $360(23.75)$ & $67(23.1)$ & & & \\
\hline Alcohol use in the past month $\ddagger$ & & & $0.01^{*}$ & & \\
\hline Never & $474(31.27)$ & $80(27.49)$ & & & \\
\hline Less than once/week & $593(39.12)$ & $104(35.74)$ & & & \\
\hline At least once/week & $253(16.69)$ & $50(17.18)$ & & & \\
\hline At least three times/week & $140(9.23)$ & $40(13.75)$ & & & \\
\hline Almost everyday & $56(3.69)$ & $17(5.84)$ & & & \\
\hline Illicit drug use in the past 6 mont & ths $\ddagger$ & & $0.62 \dagger$ & & \\
\hline No & $1454(97)$ & $278(97.54)$ & & & \\
\hline Yes & $45(3)$ & $7(2.46)$ & & & \\
\hline $\begin{array}{l}\text { Diagnosed with STD by doctors } \\
\text { in the past } 6 \text { months }^{*}\end{array}$ & & & $<0.01 \dagger$ & & \\
\hline No & 1407 (92.93) & 257 (88.32) & & & \\
\hline Yes & $107(7.07)$ & $34(11.68)$ & & & \\
\hline Commercial sexual services in th & ne past 6 monthsł & & $0.37 \dagger$ & & \\
\hline No & $1430(94.45)$ & 271 (93.13) & & & \\
\hline Yes & $84(5.55)$ & $20(6.87)$ & & & \\
\hline
\end{tabular}

${ }^{\star}$ Rank-sum test.

$+\chi^{2}$ test;

†Indicates loss of data.

MSM, men who have sex with men; MSMO, men who have sex with men only; MSMW, men who have sex with men and women; STD, sexually transmitted disease.

$291(16.1 \%)$ were classified as MSMW according to the number of female sexual partners in the past 6 months they reported.

The demographic characteristics, HIV-related characteristics and substance use rates of the MSMO and MSMW are shown in table 1 . The median age of the MSMO group was 27 years (IQR: 23-33) compared with 34 years (IQR: 27-40) for the MSMW group. Univariate analyses indicated that MSMW were more likely than MSMO to be married, be part of rural households, have a lower HIV knowledge score, perceive a higher AIDS threat to themselves and their families and engage in less unprotected oral sex with their male partners in the past month. After adjusting for demographic and HIV-related characteristics, these differences persisted and were statistically significant $(p<0.05)$. MSMW were also likely to be older, have a lower education level and have been diagnosed with an STD by doctors in the past 6 months and were less likely to report ever having HIV testing and counselling than MSMO. Although the direction of these associations remained after adjusting for demographic and HIV-related characteristics, the associations were no longer statistically significant. 
Table 2 Depression, anxiety and comorbidity between MSMW and MSMO

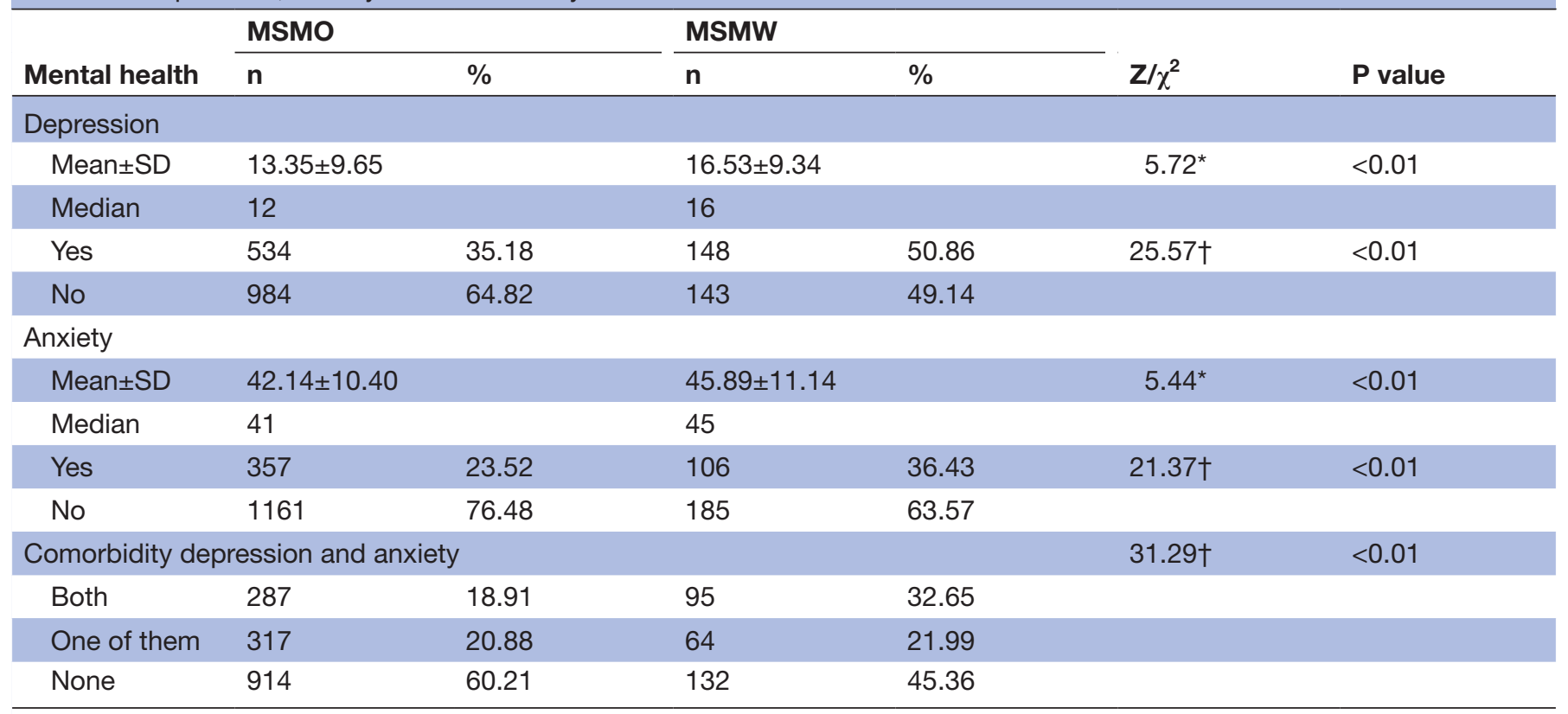

${ }^{*}$ Rank-sum test.

† $\chi 2$ test.

MSMO, men who have sex with men only; MSMW, men who have sex with men and women.

Among MSMO, the median depression score was 12 (IQR: 6-19), the prevalence of depression was $35.18 \%$, the median score was 16 (IQR: 9-23) and the prevalence was $50.86 \%$ among MSMW (table 2). Both the rank test and the Wald $\chi^{2}$ test showed statistical significance. The prevalence of anxiety was greater and the anxiety score was higher among MSMW than among MSMO ( $\mathrm{p}<0.01)$. The prevalence of comorbidity was $18.91 \%$ among MSMO compared with $32.65 \%$ among MSMW. Among MSMO, the proportion of men without depression and anxiety was $60.21 \%$ compared with less than half among MSMW $(45.36 \%)$. The correlation coefficient of the scores for depression and anxiety was 0.70 for MSMW and 0.72 for MSMO.

The results of a multivariate logistic regression analysis using depression and anxiety as independent variables are shown in tables 3 and 4 . The results showed that after adjusting for potential confounding factors, the prevalence of depression and anxiety was 1.89 (95\% CI 1.42 to 2.53) and 1.71 (95\% CI 1.25 to 2.33 ) times higher among MSMW than among MSMO, respectively.

The prevalence of depression was associated with educational level (college or above vs primary or below: OR $0.41,95 \%$ CI 0.21 to 0.78 ) and monthly income (30015000 vs $\leq 1000$ : OR $0.61,95 \%$ CI 0.44 to 0.84$)$; $\geq 5001$ vs $\leq 1000$ : OR $0.48,95 \%$ CI 0.32 to 0.73 ).

The prevalence of depression was higher among those who had never engaged in HIV counselling and those who perceived a high rate of HIV infection among MSM in the city where they lived. Compared with participants who reported only ' 1 ' for their sexual role, participants who reported both ' 0 ' and ' 1 ' for their sexual roles and participants who reported only ' 0 ' for their sexual role showed higher rates of depression (OR 1.32, 95\% CI 1.02 to 1.70 ; OR $1.86,95 \%$ CI 1.25 to 2.76 ). Participants who sometimes/always looked for sexual partners through the internet had a higher prevalence of depression than those who never searched for partners using these methods (OR 1.61, 95\% CI 1.22 to 2.16). The prevalence of depression was lower for those who drank less than once a week than for those who never drank, while the prevalence of depression was higher for those who almost drank every day than for those who never drank (table 3).

A high prevalence of anxiety was associated with young age (16-25 years vs $18-25$ years: OR $0.73,95 \% \mathrm{CI}$ 0.56 to $0.96 ; \geq 35$ years vs $18-25$ years: OR $0.65,95 \%$ CI 0.47 to 0.90 ), lower education level and lower HIV score. The prevalence of anxiety was higher for those who perceived a high rate of HIV infection among MSM in the city where they lived. Participants who sometimes/always looked for sexual partners through the internet had a higher prevalence of anxiety than those who had never looked for partners using these methods (OR 1.44, 95\% CI 1.07 to 1.94) and those who had obtained commercial sexual services in the past 6 months. Anxiety was lower among those who drank less than once a week than among those who never drank (OR $0.63,95 \%$ CI 0.47 to 0.83 ). There was no significant difference between drug use and the prevalence of anxiety and depression (table 4).

\section{DISCUSSION}

This cross-sectional study found that the prevalence of depression, anxiety and comorbidity was higher among HN MSMW than among MSMO. When compared with 
Table 3 Multivariate logistic stepwise regression results with depression as the dependent variable

\begin{tabular}{|c|c|c|c|c|c|}
\hline Variable & b & $\mathbf{S}$ & $\chi^{2}$ & $P$ value & OR (95\% Cl) \\
\hline \multicolumn{6}{|c|}{ The no of female sexual partners in the past 6 months } \\
\hline MSMO (0) & Ref & & & & \\
\hline MSMW (>0) & 0.64 & 0.15 & 18.60 & $<0.01$ & 1.89 (1.42 to 2.53$)$ \\
\hline \multicolumn{6}{|l|}{ Educational level } \\
\hline Primary or below & Ref & & & & \\
\hline Junior high & -0.46 & 0.36 & 1.63 & 0.20 & $0.63(0.31$ to 1.28$)$ \\
\hline Senior high & -0.56 & 0.34 & 2.80 & 0.10 & 0.57 (0.30 to 1.10$)$ \\
\hline Junior college & -0.58 & 0.34 & 2.89 & 0.09 & 0.56 (0.29 to 1.09$)$ \\
\hline College or above & -0.90 & 0.34 & 7.29 & $<0.01$ & $0.41(0.21$ to 0.78$)$ \\
\hline \multicolumn{6}{|l|}{ Monthly income (¥) } \\
\hline$\leq 1000$ & Ref & & & & \\
\hline $1001-3000$ & -0.17 & 0.16 & 1.15 & 0.28 & 0.84 (0.61 to 1.15$)$ \\
\hline $3001-5000$ & -0.49 & 0.16 & 9.09 & $<0.01$ & 0.61 (0.44 to 0.84$)$ \\
\hline$\geq 5001$ & -0.73 & 0.21 & 11.86 & $<0.01$ & $0.48(0.32$ to 0.73$)$ \\
\hline \multicolumn{6}{|l|}{ HIV counselling } \\
\hline No & Ref & & & & \\
\hline Yes & -0.52 & 0.11 & 23.02 & $<0.01$ & 0.59 (0.48 to 0.73$)$ \\
\hline
\end{tabular}

Perceived the rate of HIV infection among MSM in the city where they live

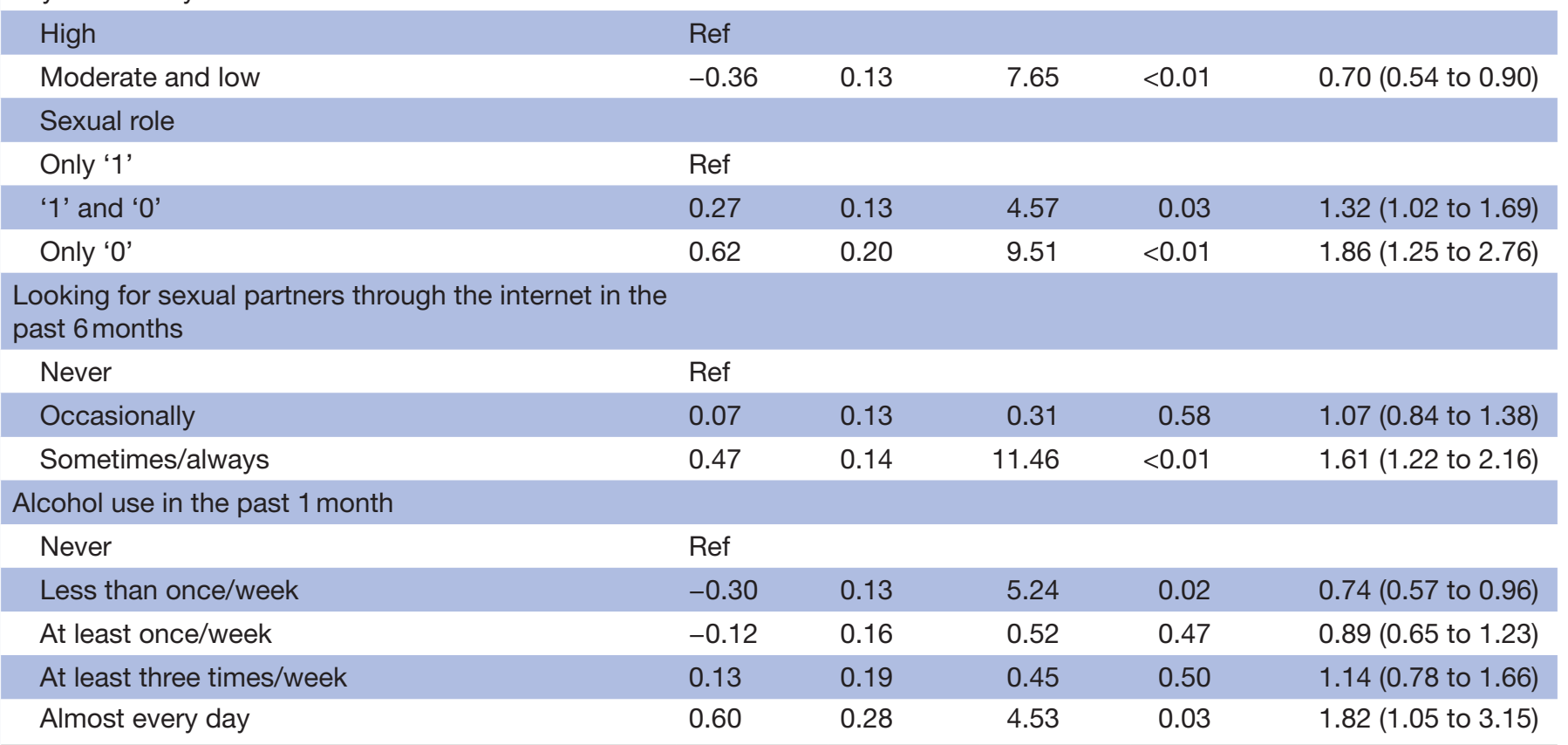

MSM, men who have sex with men; MSMO, men who have sex with men only; MSMW, men who have sex with men and women.

the Chinese general population, MSMW had a higher score for depression $(13.24 \pm 10.33) .{ }^{36}$ However, there were no significant differences in depression scores between MSMO and the general population.

Although numerous studies have demonstrated that the prevalence of depression and anxiety among MSM is higher than that of the general population, ${ }^{37-41}$ few studies have compared the differences between MSMW and MSMO. Our study indicates that MSMW show a higher prevalence of depression and anxiety than MSMO after adjusting for potential confounding factors, which is consistent with another study conducted in the USA. ${ }^{26}$ One possible explanation for why MSMW report more mental health problems is their high gender role conflict, which Bingham et al described as 'internal conflict with traditional gender role stereotypes and an individual's perceived need to comply with these roles' . ${ }^{42}$ In addition, $16.1 \%(291 / 1518)$ of MSM were classified as MSMW in this study, which is higher than the rates observed in 13 European cities $(12.64 \%, 589 / 4658),{ }^{22}$ and nearly $70 \%$ of 
Table 4 Multivariate logistic stepwise regression results with anxiety as the dependent variable

\begin{tabular}{|c|c|c|c|c|c|}
\hline Variable & b & $\mathbf{s}$ & $\chi^{2}$ & $P$ value & OR $(95 \% \mathrm{Cl})$ \\
\hline \multicolumn{6}{|c|}{ The no of female sexual partners in the past 6 months } \\
\hline MSMO (0) & Ref & & & & \\
\hline MSMW (>0) & 0.53 & 0.16 & 11.36 & $<0.01$ & 1.71 (1.25 to 2.33$)$ \\
\hline \multicolumn{6}{|l|}{ Age } \\
\hline 18-25years old & Ref & & & & \\
\hline 26-35 years old & -0.32 & 0.14 & 5.25 & 0.02 & 0.73 (0.56 to 0.96$)$ \\
\hline Older than 35 years old & -0.43 & 0.17 & 6.90 & $<0.01$ & 0.65 (0.47 to 0.90$)$ \\
\hline \multicolumn{6}{|l|}{ Educational level } \\
\hline Primary or below & Ref & & & & \\
\hline Junior high & -0.43 & 0.35 & 1.51 & 0.22 & 0.65 (0.33 to 1.29$)$ \\
\hline Senior high & -0.76 & 0.33 & 5.43 & 0.02 & 0.47 (0.25 to 0.89$)$ \\
\hline Junior college & -0.83 & 0.33 & 6.32 & 0.01 & 0.44 (0.23 to 0.83$)$ \\
\hline College or above & -1.29 & 0.33 & 15.36 & $<0.01$ & $0.28(0.15$ to 0.53$)$ \\
\hline
\end{tabular}

HIV knowledge score

\begin{tabular}{|c|c|c|c|c|c|}
\hline$<11$ & Ref & & & & \\
\hline$\geq 11$ & -0.30 & 0.14 & 4.48 & 0.03 & 0.74 (0.57 to 0.98$)$ \\
\hline Perceived the rate of HIV infe & ity wher & $y$ live & & & \\
\hline High & Ref & & & & \\
\hline Moderate and low & -0.40 & 0.14 & 8.41 & $<0.01$ & 0.67 (0.51 to 0.88$)$ \\
\hline Looking for sexual partners th & ast $6 \mathrm{mc}$ & & & & \\
\hline Never & Ref & & & & \\
\hline Occasionally & -0.09 & 0.14 & 0.42 & 0.52 & 0.91 (0.69 to 1.21$)$ \\
\hline Sometimes/always & 0.36 & 0.15 & 5.73 & 0.02 & 1.44 (1.07 to 1.94$)$ \\
\hline Alcohol use in the past month & & & & & \\
\hline Never & Ref & & & & \\
\hline Less than once/week & -0.47 & 0.15 & 10.21 & $<0.01$ & 0.63 (0.47 to 0.83 ) \\
\hline At least once/week & -0.19 & 0.18 & 1.12 & 0.29 & 0.83 (0.59 to 1.17$)$ \\
\hline At least three times/week & 0.08 & 0.20 & 0.17 & 0.68 & 1.09 (0.73 to 1.62$)$ \\
\hline Almost every day & 0.01 & 0.29 & 0.01 & 0.97 & 1.01 (0.57 to 1.79 ) \\
\hline Commercial sexual services ir & & & & & \\
\hline No & Ref & & & & \\
\hline Yes & 0.47 & 0.23 & 4.32 & 0.04 & 1.60 (1.03 to 2.50$)$ \\
\hline
\end{tabular}

MSM, men who have sex with men; MSMO, men who have sex with men only; MSMW, men who have sex with men and women.

MSMW were married or divorced, in accordance with the results from Zhang et al. ${ }^{43}$ The Chinese traditional value of 'having a son to carry on the family name' may create more stress for MSMW because those who are married may be struggling and caught in a dilemma of whether they should disclose their sexual orientation to their family members. Mirandola et $a t^{22}$ found that MSMW were less likely than MSMO to be open with their family and friends about their sexual attraction. As a result, MSMW may lack social support, making them vulnerable to mental health problems. ${ }^{44}$

In line with other studies, ${ }^{25}{ }^{45}$ this study revealed that MSM with higher education levels and higher income were less likely to suffer from anxiety and depression.
Low socioeconomic status was associated with depression, which was also reported in the general population. ${ }^{46}$ Younger MSM had a higher prevalence of anxiety than older MSM, indicating that older people have greater resilience, which is consistent with the results of McGowan et $a l .{ }^{47}$ Additionally, MSM who perceived higher rates of HIV infection among MSM in their cities were more likely to report depression and anxiety, and those who lacked HIV knowledge were more likely to experience anxiety, suggesting that their own incorrect understanding of HIV and high threat perception contributed to certain psychological burdens, rendering them more likely to experience mental health problems. 
In the present study, we found that the prevalence of depression and anxiety was related to some risky sexual behaviour. Among MSM, there was a high frequency of looking for partners through the internet, never having HIV counselling, receiving commercial sexual services in the past 6 months and mainly playing a ' 0 ' role in their sexual behaviour, which is consistent with the results of studies conducted in other countries. ${ }^{48-50}$ A relationship between mental health and risky sexual behaviour has been reported, ${ }^{51}{ }^{52}$ although the mechanism is relatively limited. One study conducted in metro Vancouver offered the interpretation that polydrug use partially mediated the relationship between depression and risky sexual behaviour. ${ }^{53}$

When we examined the relationship between substance use and depression and anxiety, no associations were found between the illicit use of any drug and mental health. However, this finding should be interpreted with caution given that the number of drug users in this study was low $(3 \%, 52 / 1784)$, and previous studies have shown relationships between illicit drug use and depression and anxiety in MSM, women and other groups. ${ }^{53-57}$ Co-occurrence of illicit drug use and depression contributing to an increased risk for high-risk sex was also reported. ${ }^{5358}$ Thus, more studies should be conducted in China in the future to verify the relationship between drug use and depression among MSM. The prevalence of anxiety and depression was lower among MSM who reported moderate drinking (once a week) than among those who never drank, while the prevalence was higher among MSM who drank almost every day than among those who never drank. Drinking (once a week) may occur as part of interpersonal communications, and moderate social interaction contributes to alleviating stress, while excessive drinking (almost every day) is harmful to physical and mental health.

This study highlights the need to address mental health among MSMW rather than merely focusing on comparisons between MSM and the general population. Although this study focused only on HN MSMW, it is possible that HP MSMW have more severe mental health problems; thus, future studies should be conducted. HN MSMW reported high rates of depression, anxiety and comorbidity, which could be attributed to the potential existence of internal status (gender role conflict ${ }^{42}$ ) and external environment. MSMW may identify themselves as neither gay nor heterosexual, leading to internal gender role conflict. Furthermore, stigma, prejudice and discrimination ${ }^{59}$ are possible in the external environment. Based on the findings of this and other studies, ${ }^{6061}$ it is essential for MSMW to establish a sound social support system consisting of the combined efforts of family, friends, female partners and society. Providing MSMW with adequate support is beneficial in helping them to overcome difficult situations. Furthermore, as the relationship between mental health and risky sexual behaviour has been documented, future health interventions could integrate mental health services and HIV prevention programmes and should consider the differences between MSMW and MSMO.
This study has some shortcomings. First, we recruited the participants by non-probability sampling, which may lead to some bias and limit the generalisability of this study. Second, in this paper, MSMW were identified based on whether they had female sexual partners in the past 6 months. Ramakrishnan $e t a l^{21}$ classified MSMW in the past month as the standard, and Davis et al, ${ }^{62}$ Phillips et $a b^{63}$ and Tao $e t a l^{20}$ defined MSMW based on a longer time (a year or ever). A reasonable unified standard to identify the MSMW group is expected in future studies. In addition to the serological status of HIV, other information was self-reported. The results for some sensitive issues may therefore be biased. Furthermore, this study involved only a cross-sectional survey. Cohort studies could be conducted to confirm these findings in subsequent studies.

\section{CONCLUSION}

In summary, this study found a higher prevalence of depression, anxiety and comorbidity and associated factors for depression and anxiety among HN MSMW than among MSMO. Our findings suggest the need to address mental health among MSMW. Future health intervention strategies should integrate mental health services and traditional HIV prevention programmes and should consider the differences between MSMW and MSMO.

\section{Author affiliations}

${ }^{1}$ Department of Health Statistics and Information Management, School of Public Health and Management, Chongqing Medical University, Chongqing, China ${ }^{2}$ Department of Epidemiology and Medical Statistics, School of Public Health, Guangxi Medical University, Nanning, China

${ }^{3}$ Department of Epidemiology and Health Statistics, School of Public Health, Xinjiang Medical University, Xinjiang, China

${ }^{4}$ Department of Epidemiology and Medical Statistics, School of Public Health, Sichuan University, Sichuan, China

${ }^{5}$ Hospital of Sichuan International Studies University, Chongqing, China

${ }^{6}$ Key Laboratory of Molecular Biology on Infectious Diseases, Ministry of Education, Chongqing Medical University, Chongqing, China

Acknowledgements We thank all participants and investigators in Chongqing, Sichuan, Xinjiang and Guangxi for their help.

Contributors YH performed the data analyses and wrote the manuscript. X-NZ was involved in the design of the study and collecting data in Chongqing, as well as the revision of the manuscript. BP, YZ, HL, J-HD, JZ and A-LH were involved in the design of the study and collecting data. $X-\mathrm{HZ}$ contributed to the revision of the manuscript.

Funding This study was supported by the National Key Project for Infectious Diseases of the Ministry of Science and Technology of China (grant number 2012ZX10001007-007) and Chongqing Science and Technology Commission (No. cstc2013jcyjA10009).

Competing interests None declared.

Patient consent for publication Not required.

Ethics approval The Ethics Committee of Chongqing Medical University has approved the study (2012010).

Provenance and peer review Not commissioned; externally peer reviewed. Data sharing statement No additional data are available.

Open access This is an open access article distributed in accordance with the Creative Commons Attribution Non Commercial (CC BY-NC 4.0) license, which 
permits others to distribute, remix, adapt, build upon this work non-commercially, and license their derivative works on different terms, provided the original work is properly cited, appropriate credit is given, any changes made indicated, and the use is non-commercial. See: http://creativecommons.org/licenses/by-nc/4.0/.

\section{REFERENCES}

1. UNAIDS. Unaids data 2017. 2017 http://www.unaids.org/sites/ default/files/media_asset/20170720_Data_book_2017 en.pdf.

2. Qin Q, Guo W, Tang W, et al. Spatial analysis of the human immunodeficiency virus epidemic among Men Who Have Sex with Men in China, 2006-2015. Clin Infect Dis 2017;64:956-63.

3. Cdc C. update on the AIDS/STD epidemic in China. Chinese Journal of AIDS\&STD 2017;24:111.

4. Jeffries WL. Beyond the bisexual bridge: sexual health among U.S. men who have sex with men and women. Am J Prev Med 2014;47:320-9.

5. Guo Y, Li X, Song Y, et al. Bisexual behavior among Chinese young migrant men who have sex with men: implications for HIV prevention and intervention. AIDS Care 2012;24:451-8.

6. Reisner SL, Mimiaga MJ, Skeer M, et al. Clinically significant depressive symptoms as a risk factor for HIV infection among black MSM in Massachusetts. AIDS Behav 2009;13:798-810.

7. Salomon EA, Mimiaga MJ, Husnik MJ, et al. Depressive symptoms, utilization of mental health care, substance use and sexual risk among young men who have sex with men in EXPLORE: implications for age-specific interventions. AIDS Behav 2009;13:811-21.

8. Rogers G, Curry M, Oddy J, et al. Depressive disorders and unprotected casual anal sex among Australian homosexually active men in primary care. HIV Med 2003;4:271-5.

9. Fendrich M, Avci O, Johnson TP, et al. Depression, substance use and HIV risk in a probability sample of men who have sex with men. Addict Behav 2013;38:1715-8.

10. Mimiaga MJ, Biello KB, Sivasubramanian M, et al. Psychosocial risk factors for HIV sexual risk among Indian men who have sex with men. AIDS Care 2013;25:1109-13.

11. Lelutiu-Weinberger C, Pachankis JE, Golub SA, et al. Age cohort differences in the effects of gay-related stigma, anxiety and identification with the gay community on sexual risk and substance use. AIDS Behav 2013;17:340-9.

12. Moraes RP, Casseb J. Depression and adherence to antiretrovira treatment in HIV-positive men in São Paulo, the largest city in South America: Social and psychological implications. Clinics 2017;72:743-9.

13. Hawton K, Casañas I Comabella C, Haw C, et al. Risk factors for suicide in individuals with depression: a systematic review. J Affect Disord 2013;147:17-28.

14. Wu YL, Yang HY, Wang J, et al. Prevalence of suicidal ideation and associated factors among HIV-positive MSM in Anhui, China. Int $J$ STD AIDS 2015;26:496-503.

15. Cho B, Sohn A. How do sexual identity, and coming out affect stress, depression, and suicidal ideation and attempts among men who have sex with men in South Korea? Osong Public Health Res Perspect 2016;7:281-8.

16. Wells KB, Golding JM, Burnam MA. Chronic medical conditions in a sample of the general population with anxiety, affective, and substance use disorders. Am J Psychiatry 1989;146:1440-6.

17. McEvoy PM, Grove R, Slade T. Epidemiology of anxiety disorders in the Australian general population: findings of the 2007 Australian National Survey of Mental Health and Wellbeing. Aust N Z J Psychiatry 2011:45:957-67.

18. Seligman LD, Ollendick TH. Comorbidity of anxiety and depression in children and adolescents: an integrative review. Clin Child Fam Psychol Rev 1998;1:125-44.

19. Stuart S, Couser G, Schilder K, et al. Postpartum anxiety and depression: onset and comorbidity in a community sample. J Nerv Ment Dis 1998;186:420-4.

20. Tao J, Ruan Y, Yin L, et al. Sex with women among men who have sex with men in China: prevalence and sexual practices. AIDS Patient Care STDS 2013;27:524-8.

21. Ramakrishnan L, Ramanathan S, Chakrapani V, et al. Comparison of Sexual Risk, HIV/STI prevalence and intervention exposure among men who have sex with men and women (msmw) and men who have sex with men only (msmo) in india: implications for HIV Prevention. AIDS Behav 2015;19:2255-69.

22. Mirandola M, Gios L, Sherriff N, et al. Socio-demographic characteristics, sexual and test-seeking behaviours amongst men who have sex with both men and women: results from a bio-behavioural survey in 13 European Cities. AIDS Behav 2017;21:3013-25.

23. Hylton E, Wirtz AL, Zelaya CE, et al. Sexual identity, stigma, and depression: the role of the "anti-gay propaganda law" in mental health among men who have sex with men in Moscow, Russia. Journal of Urban Health 2017;94:319-29.

24. Jorm AF, Korten AE, Rodgers B, et al. Sexual orientation and mental health: results from a community survey of young and middle-aged adults. Br J Psychiatry 2002;180:423-7.

25. Millar BM, Starks TJ, Grov C, et al. Sexual risk-taking in hiv-negative gay and bisexual men increases with depression: results from a u.s. national study. AIDS Behav 2017;21:1665-75.

26. Dyer TP, Regan R, Wilton L, et al. Differences in substance use, psychosocial characteristics and HIV-related sexual risk behavior between Black men who have sex with men only (BMSMO) and Black men who have sex with men and women (BMSMW) in six US cities. J Urban Health 2013;90:1181-93.

27. Blashill AJ, O'Cleirigh $\mathrm{C}$, Mayer $\mathrm{KH}$, et al. Body mass index, depression and sexual transmission risk behaviors among HIVpositive MSM. AIDS Behav 2012;16:2251-6.

28. Brown MJ, Serovich JM, Kimberly JA. Perceived intentional transmission of HIV infection, sustained viral suppression and psychosocial outcomes among men who have sex with men living with HIV: a cross-sectional assessment. Sex Transm Infect 2018;94:sextrans-2017-053153.

29. Mgopa LR, Mbwambo J, Likindikoki S, et al. Violence and depression among men who have sex with men in Tanzania. BMC Psychiatry 2017;17:296.

30. Radloff LS. The CES-D scale a self-report depression scale for research in the general population. Applied Psychological Measurement 1977:1:385-401.

31. Haringsma R, Engels GI, Beekman AT, et al. The criterion validity of the Center for Epidemiological Studies Depression Scale (CES-D) in a sample of self-referred elders with depressive symptomatology. Int J Geriatr Psychiatry 2004;19:558-63.

32. Zhang J, Sun W, Kong Y, et al. Reliability and validity of the ces-d scale in two special adult samples from rural China. Compr Psychiatry 2012;53:1243-51.

33. Beekman AT, Deeg DJ, Van Limbeek J, et al. Criterion validity of the Center for Epidemiologic Studies Depression scale (CES-D): results from a community-based sample of older subjects in The Netherlands. Psychol Med 1997;27:231-5.

34. Zung WWK. A rating instrument for anxiety disorders. Psychosomatics 1971;12:371-9.

35. Zhang Y, Liu R, Li G, et al. The reliability and validity of a Chineseversion Short Health Anxiety Inventory: an investigation of university students. Neuropsychiatr Dis Treat 2015;11:1739.

36. Zhang J, et al. Development of the Chinese age norms of CES-D in urban area. Chinese Mental Health Journal 2010.

37. Tomori C, McFall AM, Srikrishnan AK, et al. Diverse rates of depression among men who have sex with men (msm) across india: insights from a multi-site mixed method study. AIDS Behav 2016;20:304-16.

38. Parker RD, Lõhmus L, Valk $A$, et al. Outcomes associated with anxiety and depression among men who have sex with men in Estonia. J Affect Disord 2015;183:205-9.

39. Meyer IH, Dietrich J, Schwartz S. Lifetime prevalence of mental disorders and suicide attempts in diverse lesbian, gay, and bisexual populations. Am J Public Health 2008;98:1004-.

40. Secor AM, Wahome E, Micheni M, et al. Depression, substance abuse and stigma among men who have sex with men in coastal Kenya. AIDS 2015;29 Suppl 3:101-2.

41. Pan X, Li R, Ma Q, et al. Sexual risk behaviour, sexual victimisation, substance use and other factors related to depression in men who have sex with men in Wenzhou, China: a cross-sectional study. BMJ Open 2018;8(4):bmjopen-2016-013512--2010.

42. Bingham TA, Harawa NT, Williams JK. Gender role conflict among African American men who have sex with men and women: associations with mental health and sexual risk and disclosure behaviors. Am J Public Health 2013;103:127-33.

43. Zhang $B$, et al. HIV/AIDS interventions targeting men who have sex with men:theory and practice. Journal for China Aids/std 2000.

44. Yang C, Latkin C, Tobin K, et al. Informal social support and depression among african american men who have sex with men. $J$ Community Psychol 2013;41:435-45.

45. De Santis JP, Colin JM, Provencio Vasquez E, et al. The relationship of depressive symptoms, self-esteem, and sexual behaviors in a predominantly Hispanic sample of men who have sex with men. Am $J$ Mens Health 2008;2:314-

46. Topuzoğlu A, Binbay T, Ulaș H, et al. The epidemiology of major depressive disorder and subthreshold depression in Izmir, Turkey: 
Prevalence, socioeconomic differences, impairment and helpseeking. J Affect Disord 2015;181:78-86.

47. McGowan J, Sherr L, Rodger A, et al. Effects of age on symptom burden, mental health and quality of life amongst people with HIV in the UK. J Int AIDS Soc 2014;17:19511.

48. Klein $\mathrm{H}$. Mental health functioning among men who use the internet specifically to find partners for unprotected sex. Ment IIIn 2013;5:6-25.

49. Miltz AR, Rodger AJ, Sewell J, et al. Clinically significant depressive symptoms and sexual behaviour among men who have sex with men. BJPsych Open 2017;3:127-37.

50. Wim VB, Christiana N, Marie L. Syndemic and other risk factors for unprotected anal intercourse among an online sample of Belgian HIV negative men who have sex with men. AIDS Behav 2014;18:50-8.

51. Mercer $\mathrm{CH}$, Prah P, Field $\mathrm{N}$, et al. The health and well-being of men who have sex with men (MSM) in Britain: Evidence from the third National Survey of Sexual Attitudes and Lifestyles (Natsal-3). BMC Public Health 2016;16:1-16.

52. Ahaneku H, Ross MW, Nyoni JE, et al. Depression and HIV risk among men who have sex with men in Tanzania. AIDS Care 2016;28 Suppl 1:140-7.

53. Card KG, Lachowsky NJ, Armstrong HL, et al. The additive effects of depressive symptoms and polysubstance use on HIV risk among gay, bisexual, and other men who have sex with men. Addict Behav 2018;82:158-.

54. Illangasekare SL, Burke JG, McDonnell KA, et al. The impact of intimate partner violence, substance use, and HIV on depressive symptoms among abused low-income urban women. J Interpers Violence 2013:28:2831-

55. Rahman M, Nakamura K, Seino K, et al. Do tobacco smoking and illicit drug/alcohol dependence increase the risk of mental disorders among men? Evidence from a national urban Bangladeshi sample. Perspect Psychiatr Care 2015;51:16-27.

56. Rasic $D$, Weerasinghe $S$, Asbridge $M$, et al. Longitudinal associations of cannabis and illicit drug use with depression, suicidal ideation and suicidal attempts among Nova Scotia high school students. Drug Alcohol Depend 2013;129(1-2):49-53.

57. Choi NG, DiNitto DM, Marti CN, et al. Relationship between marijuana and other illicit drug use and depression/suicidal thoughts among late middle-aged and older adults. Int Psychogeriatr 2016;28:577-89.

58. Santos GM, Do T, Beck J, et al. Syndemic conditions associated with increased HIV risk in a global sample of men who have sex with men. Sex Transm Infect 2014;90:250-3.

59. Meyer IH. Prejudice, social stress, and mental health in lesbian, gay, and bisexual populations: conceptual issues and research evidence. Psychol Bull 2003;129:674-97.

60. Allen VC, Myers HF, Williams JK. Depression among Black bisexual men with early and later life adversities. Cultur Divers Ethnic Minor Psychol 2014;20:128-37.

61. Benoit E, Koken JA. Perspectives on substance use and disclosure among behaviorally bisexual black men with female primary partners. J Ethn Subst Abuse 2012;11:294-317.

62. Davis A, Best J, Wei C, et al. Intimate partner violence and correlates with risk behaviors and hiv/sti diagnoses among men who have sex with men and men who have sex with men and women in China: A Hidden Epidemic. Sex Transm Dis 2015;42:387-.

63. Phillips AE, Lowndes CM, Boily MC, et al. Men who have sex with men and women in Bangalore, South India, and potential impact on the HIV epidemic. Sex Transm Infect 2010;86:187-92. 